\title{
A comparison of laryngeal mask airway- supreme and endotracheal tube use with respect to airway protection in patients undergoing septoplasty: a randomized, single-blind, controlled clinical trial
}

Erol Karaaslan ${ }^{1 *}$, Sedat Akbas ${ }^{1}$, Ahmet Selim Ozkan ${ }^{1}$, Cemil Colak² and Zekine Begec ${ }^{1}$

\begin{abstract}
Background: There are doubts among anesthesiologists on the use of the Laryngeal Mask Airway (LMA) in nasal surgeries because of concerns about the occurrence of blood leakages to the airway. We hypothesized that the use of LMA-Supreme (LMA-S) in nasal surgery is comparable with endotracheal tube (ETT) according to airway protection against blood leakage through the fiberoptic bronchoscopy, oropharyngeal leakage pressure (OLP), heart rate (HR), mean arterial pressure (MAP), and postoperative adverse events.

Methods: The present study was conducted in a prospective, randomized, single-blind, controlled manner on 80 patients, who underwent septoplasty procedures under general anesthesia, after dividing them randomly into two groups according to the device used (LMA-S or ETT). The presence of blood in the airway (glottis/trachea, distal trachea) was analyzed with the fiberoptic bronchoscope and a four-point scale. Both groups were evaluated for OLP; HR; MAP; postoperative sore throat, nausea, and vomiting; dysphagia; and dysphonia.

Results: In the fiberoptic evaluation of the airway postoperatively, less blood leakage was detected in both anatomic areas in the LMA-S group than in the ETT group (glottis/trachea, $p=0.004$; distal trachea, $p=0.034$ ). Sore throat was detected less frequently in the LMA-S group at a significant level in the 2 nd, 6 th, and 12th hours of postoperative period; however, other adverse events were similar in both groups. Hemodynamic parameters were not different between the two groups.
\end{abstract}

Conclusion: The present findings demonstrate that the LMA-S provided more effective airway protection than the ETT in preventing blood leakage in the septoplasty procedures. We believe that the LMA-S can be used safely and as an alternative to the ETT in septoplasty cases.

Trial registration: This trial is registered at the US National Institutes of Health (ClinicalTrials.gov) \# NCT03903679 on April 5, 2019.

Keywords: Airway protection, LMA supreme, Septoplasty, Fiberoptic bronchoscopy, Sore throat

\footnotetext{
* Correspondence: erkara44@hotmail.com

${ }^{1}$ Department of Anesthesiology and Reanimation, Inonu University Medical Faculty, Malatya, Turkey

Full list of author information is available at the end of the article
}

(C) The Author(s). 2021 Open Access This article is licensed under a Creative Commons Attribution 4.0 International License, which permits use, sharing, adaptation, distribution and reproduction in any medium or format, as long as you give appropriate credit to the original author(s) and the source, provide a link to the Creative Commons licence, and indicate if changes were made. The images or other third party material in this article are included in the article's Creative Commons. licence, unless indicated otherwise in a credit line to the material. If material is not included in the article's Creative Commons licence and your intended use is not permitted by statutory regulation or exceeds the permitted use, you will need to obtain permission directly from the copyright holder. To view a copy of this licence, visit http://creativecommons.org/licenses/by/4.0/ The Creative Commons Public Domain Dedication waiver (http://creativecommons.org/publicdomain/zero/1.0/) applies to the data made available in this article, unless otherwise stated in a credit line to the data. 


\section{Background}

For many years, the endotracheal tube (ETT) has been accepted as the standard method for airway safety [1]. High pressure use of cuffed tubes may lead to mucosal hypoperfusion and injury [2]. The Laryngeal Mask Airway (LMA), which was first produced in the 1980s, has been used as a minimally invasive airway device in many general anesthesia practices and has become an alternative to the ETT in many surgeries [3-5].

The LMA has many advantages over the ETT, such as having no direct contact with the tracheal mucosa, no need for direct laryngoscopy during inserting, and less adverse events such as lower frequency of coughing and decreased oxygen saturation during emergence, and lower incidence of sore throat in adults [6]. In recent years, new generation SADs have been developed, such as LMA-Supreme ${ }^{\mathrm{TM}}$, which is more superior than LMAClassic with respect to safety of airway management [7].

The LMA-S is one of the second-generation semi-rigid and elliptical LMAs; it can be easily and quickly inserted without placing fingers in the patient's mouth, and it does not include latex. These second-generation models were designed to provide higher sealing pressures than the LMA-Classic. In addition, they have a duct for facilitating early identification of regurgitation prior to aspiration and also helping gastric decompression [8]. There are hesitations among anesthesiologists about using the LMA because of concerns regarding vocal cord contamination and tracheal blood leakage in nasal surgical procedures [9]. There are studies on nasal surgeries with LMA-Classic in the literature, but studies on secondgeneration LMAs, which protect the airway better than classical LMAs, are limited.

Blood leaking from the nasopharynx to the hypopharynx in nasal surgeries contaminates the vocal folds and the tracheobronchial tree. We hypothesized that the LMA-S will reduce the blood leakage to the glottis/trachea and distal trachea. The primary outcome of this study, which was conducted on septoplasty cases, was to compare the effectiveness of the LMA-S and the ETT in protecting the airway against blood leakage using fiberoptic bronchoscopy. The secondary outcome of this study was to evaluate oropharyngeal leakage pressure (OLP); hemodynamic response, including HR and MAP; and postoperative adverse events.

\section{Methods}

\section{Protocol}

This study was approved by the Local Ethics Committee (Protocol no: 2018/165) and registered at www. ClinicalTrials.gov (\# NCT03903679). We conducted a prospective, randomized, single-blind, and controlled clinical study with 80 adult patients undergoing septoplasty surgery at Inonu University Hospital, Malatya,
Turkey. This study was prepared in accordance with the Consolidated Standards of Reporting Trials (CONSORT) [10].

\section{Study design}

This study was planned as a randomized prospective study. Patients were randomly assigned to either LMA-S ( $n=40)$ or ETT $(n=40)$ group; randomization $(1: 1)$ was based on a computer generated random numbers table, using MedCalc v. 16 statistical software for Windows (medcalc.com.tr). The patients who agreed to participate voluntarily were told about the features of both airway devices to be used in airway management. The patient wasn't told which device was to be used. Patients was blinded by this method. At the same time, the nurses who had the task of evaluation in the study in PACU and the related service were blinded by not being informed about the airway device used in the operation.

\section{Study participants}

The patients agreed to participate in the study voluntarily. After they were informed about the general information of the study, they completed the written informed consent forms. The study was conducted with patients, aged 18-65, who were scheduled for elective nasal septum surgery (American Society of Anesthesiologists (ASA) I-II).

In the preoperative anesthesia evaluation, patients with scores higher than ASA II and patients who had severe respiratory, hepatic, or renal dysfunction; neurology and/ or psychiatry disorders; an allergy to anesthesia drugs, a body mass index (BMI) over 30; predictors of a difficult intubation (cervical spine pathology, modified Mallampati class 4 , or thyromental distance $<65 \mathrm{~mm}$ ); or a history of gastroesophageal reflux or hiatal hernia were excluded from the study.

\section{Preoperative procedures}

The general anesthesia was standardized for all patients. Standard monitoring consisting of noninvasive blood pressure (NIBP), pulse oximetry (SpO2), electrocardiogram (ECG) were applied to the patients who were admitted to the surgery room. Following this stage, preoperative oxygenation was performed with $100 \%$ oxygen for $3 \mathrm{~min}$ ( $\mathrm{min})$.

\section{General anesthesia}

Anesthesia induction was carried out with propofol 2.5 mg. $\mathrm{kg}^{-1}$ intravenously (IV) + remifentanil $3 \mu \mathrm{g} \cdot \mathrm{kg}^{-1}$ IV in both groups, and no myorelaxants were used. After the patients lost consciousness and following adequate mandibular relaxation, the LMA-S was inserted using a single-hand rotation technique with the cuff lubricated. The back side of the cuff was lubricated with a water- 


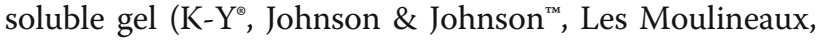
France), and the cuff of the mask was fully deflated before insertion. Airway management was performed by the same anesthesiologist, who had at least 5 years of experience. Cases in which the airway devices was not performed successfully after the second trial were excluded from the study.

The LMA-S size was chosen according to body weight in accordance with the manufacturer guidelines $(<50 \mathrm{~kg}$, size 3; 50-70 kg, size 4; 70-100 kg, size 5). After the insertion of LMA-S, if a leak sound occurs with gentle manual ventilation, a larger sized LMA-S was used which is in accordance with daily clinical practice $[11,12]$.

Cuffed endotracheal tubes with internal diameters of $7 \mathrm{~mm}$ and $8 \mathrm{~mm}$ were used for female and male patients, respectively. The LMA-S intracuff pressure of $60 \mathrm{~cm}$ $\mathrm{H}_{2} \mathrm{O}$ was adjusted to the ETT cuff pressure of $20 \mathrm{~cm}$ $\mathrm{H}_{2} \mathrm{O} / 1$ manometer (Portex Cufator Endotracheal Tube Inflator and Manometer, Portex ${ }^{\circ}$ Limited, Hythe, Kent, United Kingdom) [13]. Successful airway management was confirmed by the lack of sound from leaking air from the mouth, the expansion of the chest during ventilation, five consecutive capnography curves on the monitor, and auscultation. With the LMA-S, a nasogastric tube was inserted into the LMA drainage tube. Air leakage to the stomach was controlled by checking for bubbles (foam) at the proximal end of the nasogastric tube [14].

After successful airway management, volumecontrolled mechanical ventilation (Dräger Primus ventilator, Dräger AG, Lübeck, Germany) was initiated at a tidal volume of $8 \mathrm{ml} / \mathrm{kg}$ and a respiratory rate of 12 breaths/min; then, the respiratory rate was adjusted to maintain an $\mathrm{EtCO}_{2}$ concentration of $35-45 \mathrm{mmHg}$. Anesthesia was maintained in all patients with sevoflurane mixture of $\mathrm{FiO} 20.5$ and air. The depth of anesthesia was monitored using the Bispectral Index (BIS, VISTA Monitoring System, Massachusetts, United States of America). BIS sensors were placed in the right and left frontal areas under the hairline and covered with tape to prevent exposure to light. MAC value of Sevoflurane was titrated so that the BIS value was between 40 and 60 during operation. In addition, $0.1-0.3 \mu \mathrm{g} / \mathrm{kg} / \mathrm{min}$ IV remifentanil infusion was used.

\section{Outcome measures}

The primary outcome of the present study was to evaluate tracheal blood leakage in patients, who underwent septoplasty and whose airway patency was maintained by the LMA-S or the ETT, using a fiberoptic bronchoscope. At the end of the surgeries, a $3.5 \mathrm{~mm}$ fiberscope (Karl Storz $\mathrm{GmbH} \&$ Co. KG, Tuttlingen, Germany) was used to examine blood leakage through both airway devices (glottis/trachea, distal trachea). In the patients for whom an ETT was used, the posterior oropharynx was aspirated carefully at the end of the surgeries; after extubation, the presence of blood around the distal area of the ETT cuff was examined. To evaluate the presence of blood (glottis/ trachea, distal trachea), a four-point scale was used ( $1=$ absent, 2 = mild, $3=$ moderate, $4=$ severe) [9]. Blood leakage was evaluated by another anesthesiologist experienced with fiberoptic bronchoscopy.

The secondary outcome of the study was to evaluate OLP; hemodynamic response, including HR and MAP; adverse events, including sore throat, nausea, and vomiting; dysphagia; and dysphonia. OLPs were measured for the LMA-S and the ETT when the head was in a neutral position. The $\mathrm{O}_{2}$ flow was set to $3 \mathrm{~L} /$ min in the flowmeter, and the expiratory valve was closed. To prevent bias, one researcher covered the airway device so that the airway device type was not visible; then, another researcher checked the peak pressure value as soon as the first researcher heard an oropharyngeal leak sound, confirming that the pressure remained constant (manometer stability test) [15]. This value was recorded as the OLP. To avoid exposing the lungs to barotrauma, when the peak inspiratory pressure reached $40 \mathrm{~cm} \mathrm{H}_{2} \mathrm{O}$, the expiratory valve was opened, and the test was ended. MAP and HR were measured immediately before anesthesia induction and at the 5th, 15th, 30th min of perioperatively and 5th $\mathrm{min}$ after the extubation and airway placement were confirmed.

In the 24-h postoperative period, sore throat, nausea, vomiting, dysphagia, and dysphonia were recorded at the 2nd, 6th, 12th, and 24th hours. Sore throat was defined as continuous pain felt independently from swallowing, evaluated using a numeric rating scale (NRS) between 0 and 10. According to the NRS, the sore throat score was evaluated as "0-1 none; 2-4 mild; 5-7 moderate; and 8-10 severe" [16]. A 4-point scale was used to determine the severity of the nausea and vomiting $(0=$ no nausea, $1=$ mildmoderate nausea, $2=$ less than two vomits an hour, $3=$ more than two vomits an hour). Dysphonia was defined as difficulty in speaking because of difficult speech or pain. Dysphagia was defined as difficulty in swallowing or painful swallowing [17].

\section{Postoperative management}

The patients who opened their eyes with stimuli and had regular spontaneous breathing, a respiratory rate of $12-20 / \mathrm{min}$, and an oxygen saturation larger than $95 \%$ were extubated and taken to the recovery room. The patients were transferred to the Otorhinolaryngology ward when they achieved a modified Aldrete's score of nine or greater (on a 0-12 scale), indicating recovery sufficient for the patient to be transferred from Postoperative Care Unit (PACU) to the ward [18]. All patients received a 
standard postoperative analgesic regime of paracetamol $(1 \mathrm{~g})$ and tramadol $(1-2 \mathrm{mg} / \mathrm{kg}) \mathrm{IV}$.

\section{Sample size}

A type I error (alpha) 0.05, strength of the test (1-beta) 0.9 , effect size 0.71 for the amount of blood in the primary output variable airway (glottis/trachea), and the alternative hypothesis $(\mathrm{H} 1)$ were employed to calculate the minimum sample size. Subsequently, the minimum sample size was determined to be 40 for each group and 80 patients in total in order to find a significant difference [9]. The sample size was calculated by a web-based software (http://biostatapps.inonu.edu.tr/WSSPAS/).

\section{Statistical analysis}

Quantitative data were expressed as mean with standard deviation and median (min-max) values depending on the variable distribution, and qualitative data were summarized as frequency (percentage) for the related variables. Normality distribution was assessed using the Shapiro Wilk test. Quantitative data was analyzed using the independent samples t-test and the Mann Whitney U-test, where appropriate. Qualitative data was analyzed with the Pearson chi-square or the Fisher's exact test, where appropriate. A value of $P<0.05$ was considered as significant. IBM SPSS Statistics version 25.0 for Windows was used for the statistical analysis.

\section{Results}

A total of 80 patients were included in this study. A flow diagram is presented in Fig. 1. The age, weight, height, gender, Mallampati score, BMI, and ASA values were similar in both groups. Duration of surgery was $54.03 \pm$ $13.75 \mathrm{~min}$ and $51.48 \pm 11.92 \mathrm{~min}$ (p: 0.613) in LMA-S and ETT Groups, respectively. Duration of anesthesia was $70.95 \pm 13.55 \mathrm{~min}$ and $69.53 \pm 11.42 \mathrm{~min}$ (p: 0.378) in LMA-S and ETT Groups, respectively, and did not differ between groups. The rates of success for the first insertion attempt were not significantly different between the two groups (36 (90\%) in the LMA-S group and 34. (85\%) in the ETT group). For all patients with an unsuccessful first insertion attempt, success was achieved in the second attempt. The demographic characteristics of the patients are given in Table 1.

The blood leakage in the glottis/trachea was significantly lower in the LMA-S group in the ETT group $(p=0.004)$. The blood leakage in the distal trachea was significantly lower in the LMA-S group than in the ETT group $(p=0.034)$. OLP was $21.60 \pm 3.74 \mathrm{cmH}_{2} \mathrm{O}$ in the LMA-S group and $22.88 \pm$ $5.52 \mathrm{cmH}_{2} \mathrm{O}$ in the ETT group; there was no statistically

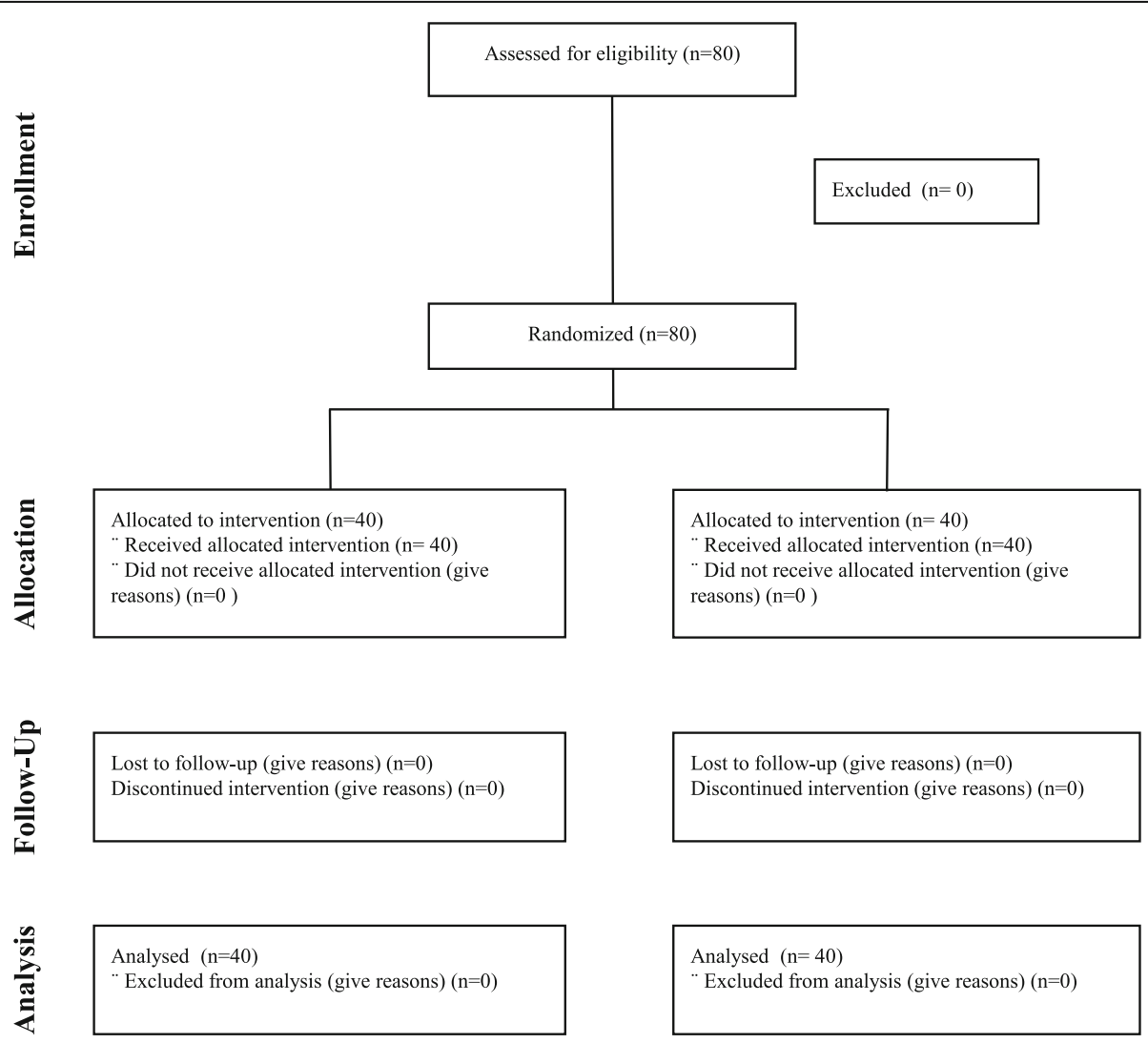

Fig. 1 Flow Diagram. CONSORT flow chart for patients' recruitment 
Table 1 Characteristics of the Patients

\begin{tabular}{|c|c|c|c|c|c|}
\hline \multirow[b]{2}{*}{ Variable } & \multicolumn{2}{|c|}{ LMA-S $(n=40)$} & \multicolumn{2}{|c|}{$\mathrm{ETT}(n=40)$} & \multirow[b]{2}{*}{$p$ value } \\
\hline & Range & Mean \pm SD or $n(\%)$ & Range & Mean \pm SD or $n(\%)$ & \\
\hline Age, years & $18-65$ & $34.18 \pm 14.16$ & $18-64$ & $35.78 \pm 13.59$ & $0.608^{a}$ \\
\hline Gender, male/female & - & $21 / 19$ & - & $19 / 21$ & $0.655^{\mathrm{b}}$ \\
\hline Height, cm & $150-183$ & $168.55 \pm 8.22$ & $152-185$ & $167.63 \pm 9.43$ & $0.642^{a}$ \\
\hline Weight, kg & $48-90$ & $67.28 \pm 9.01$ & $47-105$ & $69.63 \pm 14.60$ & $0.855^{\mathrm{a}}$ \\
\hline $\mathrm{BMI},\left(\mathrm{kg} / \mathrm{m}^{2}\right)$ & $19-29$ & $23.58 \pm 2.41$ & $18-31$ & $24.13 \pm 3.27$ & $0.323^{a}$ \\
\hline \multicolumn{6}{|l|}{ ASA, $n$} \\
\hline 1 & - & $23(57.5 \%)$ & - & $21(52.5 \%)$ & \multirow[t]{2}{*}{$0.653^{b}$} \\
\hline 2 & - & $17(42.5 \%)$ & - & $19(47.5 \%)$ & \\
\hline \multicolumn{6}{|l|}{ Mallampati Score } \\
\hline 1 & - & $25(62.5 \%)$ & - & $26(65.0 \%)$ & \multirow[t]{2}{*}{$0.816^{\mathrm{b}}$} \\
\hline 2 & - & $15(37.5 \%)$ & - & $14(35 \%)$ & \\
\hline Smoking, n (\%) & - & $12(30 \%)$ & - & $10(25 \%)$ & $0.802^{\mathrm{b}}$ \\
\hline
\end{tabular}

ASA American Society of Anesthesiology; BMI Body Mass Index; $\mathrm{cm}$ centimeter; $\mathrm{kg}$ kilogram; min minutes; $n$ number, SD Standard Deviation; a: independent samples $t$ test; $b$ : Chi-square test

significant difference between the groups $(p=0.577)$. Clinical outcome variables by airway type are presented in Table 2 .

Heart rate was significantly lower in the LMA-S group at $15 \mathrm{~min}$ after intubation than in the ETT group ( $p=$ 0.003). There was no significant difference between the groups at other time points. The HR of the patients in the two groups at various time points are presented in Table 3. MAP was significantly lower in the LMA-S group at $15 \mathrm{~min}$ after intubation than in the ETT group $(p=0.029)$. There was no significant difference between the groups at other time points. The MAP of the patients in the two groups at various time points are presented in Table 4. Sore throat was significantly higher in the ETT group at the $2 \mathrm{nd}$, 6th, and 12 th postoperative hours ( $p=0.003, p=0.017$ and $p<0.001$, respectively).

There were no differences between the groups in terms of having a sore throat at the 24th postoperative hour $(p=0.057)$. Nausea, vomiting, dysphagia, and dysphonia were similar in both groups. The postoperative adverse events are presented in Table 5.

\section{Discussion}

In this study, in which LMA-S and ETT use was compared in terms of tracheal blood leakage and adverse events in septoplasty cases, the blood leakage in the LMA-S group was statistically less than in the ETT group; this was determined by examining the airway for the presence of blood with a fiberoptic bronchoscope.

Many anesthetists and otolaryngologists are concerned about using the LMA due to concerns that blood leakage from the posterior to the hypopharynx during nasal and endoscopic sinus surgery could contaminate the vocal folds and the tracheobronchial tree, causing laryngospasm and bronchospasm. Therefore, for such operations, the ETT has been the first choice for airway safety. In the literature, there are studies comparing LMA and ETT use in nasal surgeries [9, 19]. Al-Mazrou et al. reported that LMA is a suitable method for paediatric patients undergoing sinonasal surgery [19]. However, a standardization of the cases could not be made in most studies. We achieved surgical standardization by conducting our study on septoplasty cases only. In addition, the presence of blood in the airway devices was evaluated visually, and indirect data was obtained about tracheal leakage. In our study, the presence of blood in the airway (glottis/trachea, distal trachea) was evaluated more objectively using a fiberoptic bronchoscope.

In septoplasty cases, the LMA-S avoids blood leakage to the glottis and the trachea, with its high sealing effect in the oropharynx, by surrounding the supraglottic and glottic area [9]. With the ETT, however, as the cuff is below the glottis level, blood produced during surgery can easily reach the glottis and lower parts of the airway using the outer surface of the ETT [20]. Although the ETT is considered to protect the airway better in terms of blood leakage through its traditional approach, in our study, we hypothesized that the LMA-S, which is a minimally invasive airway device with a high sealing pressure, would reduce blood leakage to the glottis-distal trachea line.

Kaplan et al. conducted a study in which 74 patients, who underwent septoplasty or endoscopic sinus surgery, were compared in terms of ETT and LMA-Classic use; they reported that the presence of blood in the glottis/ trachea level was at a less significant level in the LMAClassic group than in the ETT group [9]. However, they 
Table 2 Clinical outcomes variables by airway type

\begin{tabular}{|c|c|c|c|c|c|}
\hline \multirow[b]{2}{*}{ Variable } & \multicolumn{2}{|c|}{ LMA-S $(n=40)$} & \multicolumn{2}{|c|}{ ETT $(n=40)$} & \multirow[b]{2}{*}{ p value } \\
\hline & $\begin{array}{c}\text { Range or } \\
\text { frequency (n) }\end{array}$ & $\begin{array}{c}\text { Mean } \pm \text { SD or } \\
\text { Median }\end{array}$ & $\begin{array}{c}\text { Range or } \\
\text { frequency (n) }\end{array}$ & $\begin{array}{c}\text { Mean } \pm \text { SD or } \\
\text { Median }\end{array}$ & \\
\hline \multicolumn{6}{|l|}{ Airway blood (glottis/tracheal, score) } \\
\hline \multicolumn{6}{|l|}{1} \\
\hline \multicolumn{6}{|l|}{2} \\
\hline \multicolumn{6}{|r|}{0.004} \\
\hline \multicolumn{6}{|l|}{4} \\
\hline $1, \mathrm{n}$ & 30 & & 18 & & 0.006 \\
\hline $2, \mathrm{n}$ & 8 & & 14 & & $>0.05$ \\
\hline $3, \mathrm{n}$ & 2 & & 7 & & $>0.05$ \\
\hline $4, \mathrm{n}$ & 0 & & 1 & & $>0.05$ \\
\hline \multicolumn{6}{|l|}{ Distal Tracheal Blood (score) } \\
\hline \multicolumn{6}{|l|}{1} \\
\hline 2 & $1-2$ & 1 & $1-4$ & 1 & $a \cap a b$ \\
\hline \multicolumn{6}{|r|}{0.034} \\
\hline \multicolumn{6}{|l|}{4} \\
\hline $1, \mathrm{n}$ & 36 & & 29 & & 0.045 \\
\hline $2, \mathrm{n}$ & 4 & & 6 & & $>0.05$ \\
\hline $3, \mathrm{n}$ & 0 & & 3 & & $>0.05$ \\
\hline $4, n$ & 0 & & 2 & & $>0.05$ \\
\hline Oropharyngeal leak pressure $\left(\mathrm{cm} \mathrm{H}_{2} \mathrm{O}\right)$ & $16-32$ & $21.60 \pm 3.74$ & $18-37$ & $22.88 \pm 5.525$ & $0.577^{b}$ \\
\hline \multicolumn{6}{|l|}{ LMA, Size no } \\
\hline 3 & - & $2(5.0 \%)$ & - & - & \\
\hline 4 & - & $20(50.0 \%)$ & - & - & \\
\hline 5 & - & $18(45.0 \%)$ & - & - & \\
\hline \multicolumn{6}{|l|}{ ETT, Size no } \\
\hline 7 & - & - & - & $19(47.5 \%)$ & \\
\hline 8 & - & - & - & $21(52.5 \%)$ & \\
\hline First attempt success rate, $\mathrm{n}(\%)$ & - & $36(90 \%)$ & - & $34(85 \%)$ & $0.735^{\mathrm{a}}$ \\
\hline Duration of Anesthesia, min & $52-115$ & $70.95 \pm 13.55$ & $50-98$ & $69.53 \pm 11.42$ & $0.613^{b}$ \\
\hline Duration of Surgery, min & $35-100$ & $54.03 \pm 13.75$ & $37-88$ & $51.48 \pm 11$ & $0.378^{\mathrm{b}}$ \\
\hline
\end{tabular}

Airway blood (glottis/tracheal and distal tracheal) scores: $1=$ none, $2=$ mild, $3=$ moderate, 4 = severe; a: Chi-square test, b: independent samples $\mathrm{t}$ test. $L M A-S$ Laryngeal Mask Airway Supreme, ETT endotracheal tube

also reported that there was blood in fewer cases in the ETT group (3.2\%) than the CLMA group (19.6\%), although it was not statistically significant in the distal trachea. Kaplan et al. also reported that the ETT protected the distal trachea better. Williams et al. conducted a study with children and adult tonsillectomy cases using the LMA-Classic and the ETT; at the end of surgery, they observed less blood in the larynx and trachea in the LMA-Classic group when an evaluation was made using a fiberoptic bronchoscope [21]. This is in agreement with the results of our study. Ahmet et al. compared ETT and reinforced LMA use in 200 septal, sinus, and septal and sinus (combined) surgery patients and reported that the blood contamination was less in the LMA cuff in visual evaluation [20]. In the present study, blood leakage in the glottis/trachea and distal trachea occurred less frequently in the LMA-S (glottis/trachea: LMA-S: 10 cases (25\%), ETT: 22 cases (45\%), $p=0.004)$; 
Table 3 Heart rate of patients at various time points in two groups

\begin{tabular}{|c|c|c|c|c|c|}
\hline \multirow[t]{2}{*}{ Variable } & \multicolumn{2}{|c|}{ LMA-S $(n=40)$} & \multicolumn{2}{|c|}{ ETT $(n=40)$} & \multirow[b]{2}{*}{$p$ value } \\
\hline & Range & Mean \pm SD & Range & Mean \pm SD & \\
\hline aseline & $60-115$ & $84.50 \pm 14.65$ & $58-121$ & $82.78 \pm 14.07$ & $0,647^{a}$ \\
\hline \multicolumn{6}{|c|}{ After intubation } \\
\hline 5th $\min$ & $52-98$ & $75.20 \pm 12.07$ & 54-119 & $80,30 \pm 15.20$ & $0.127^{\mathrm{a}}$ \\
\hline 15th min & $51-90$ & $70.58 \pm 11.16$ & $53-116$ & $81.15 \pm 16.13$ & $0.003^{\mathrm{a}}$ \\
\hline 30th min & $57-96$ & $74.43 \pm 9.54$ & $60-110$ & $77.93 \pm 12.13$ & $0.264^{\mathrm{a}}$ \\
\hline
\end{tabular}

\section{After extubation}

$\begin{array}{lrrrrr}5 \text { th } \min & 56-104 & 77.25 \pm 10.60 & 63-103 & 77.73 \pm 9.98 & 0.878^{\mathrm{a}}\end{array}$

a: independent samples $t$ test;

distal trachea: LMA-S: 4 cases (10\%), ETT: 11 cases (27.5\%), $p=0.034)$. Unlike Kaplan et al., we found significantly less blood in both the glottis/trachea and the distal trachea in the LMA-S group. The reasons for the differences between the two results may be, first that our study examined only septoplasty cases, while Kaplan et al. included septoplasty, endoscopic sinus surgery, and combined septoplasty/endoscopic sinus surgery cases in their study. Second, in our study, the intracuff pressure was applied as $60 \mathrm{~mm} \mathrm{H}_{2} \mathrm{O}$ in the LMA-S and $20 \mathrm{H}_{2} \mathrm{O}$ in the ETT, but Kaplan et al. did not report any information on which intracuff pressures they used in the airway devices. Therefore, differences in cuff pressures may have affected the results. In many studies in which the LMA and the ETT were compared without using fiberoptic bronchoscopes in patients who underwent nasal and sinus surgeries, it was concluded that the LMA provided better airway protection [22]. Therefore, evaluating blood in the airway with fiberoptic bronchoscope is more objective approach than visually indirectly evaluating the presence of blood on the cuff. In summary, we

Table 4 Mean arterial pressure of patients at various timepoints in two groups

\begin{tabular}{|c|c|c|c|c|c|}
\hline \multirow[t]{2}{*}{ Variable } & \multicolumn{2}{|c|}{ LMA-S $(n=40)$} & \multicolumn{2}{|c|}{ ETT $(n=40)$} & \multirow[b]{2}{*}{$p$ value } \\
\hline & Range & Mean \pm SD & Range & Mean \pm SD & \\
\hline Baseline & $60-115$ & $89.88 \pm 13.59$ & $57-114$ & $84.23 \pm 16.18$ & $0.083^{a}$ \\
\hline \multicolumn{6}{|c|}{ After intubation } \\
\hline 5th min & $43-94$ & $70.63 \pm 11.16$ & $46-118$ & $74.30 \pm 16.06$ & $0.438^{\mathrm{a}}$ \\
\hline 15th min & $57-121$ & $71.7 \pm 14.78$ & $57-121$ & $79.03 \pm 15.04$ & $0.029^{a}$ \\
\hline 30th min & $49-98$ & $71.28 \pm 11.39$ & $47-112$ & $75.25 \pm 13.38$ & $0.260^{\mathrm{a}}$ \\
\hline
\end{tabular}

After extubation

$\begin{array}{llllll}5 \text { th } \min & 56-95 & 74.53 \pm 9.80 & 56-105 & 75.00 \pm 72.50 & 0.988^{a}\end{array}$

a: independent samples $t$ test; showed that the LMA-S provided better protection than the ETT in both anatomical regions of the airway.

Oropharyngeal leakage pressure is a gas leak occurring around the airway device. In general, the verification of the position of the airway device shows the success of positive-pressure ventilation and the degree of airway protection. It is also used to evaluate the effectiveness of different airway devices [23]. Seet et al. reported that OLP was $21 \mathrm{cmH}_{2} \mathrm{O}$ in 99 cases in which the LMA-S was used with an intracuff pressure of $60 \mathrm{cmH}_{2} \mathrm{O}$ [24]. In another study, which was conducted with the LMA-S at three different intracuff pressures $\left(80,60,40 \mathrm{H}_{2} \mathrm{O}\right)$ in 123 cases, OLP was measured as 26,20 , and $18 \mathrm{H}_{2} \mathrm{O}$, respectively [25]. In our study, the OLP value was measured as $21.60 \mathrm{cmH}_{2} \mathrm{O}$ in LMA-S and 22.8 in ETT, and did not differ between the groups. In summary, the OLP values in these other studies are consistent with our OLP values.

Postoperative sore throat is among the pharyngolaryngeal adverse events that commonly occur after general anesthesia, decreasing patient satisfaction and causing prolonged hospital stays. In addition to the direct trauma of the rigid materials that are inserted in the upper airway, the physical tension caused by the laryngoscopy, tube size, gender, surgery type, and cuff pressures may cause postoperative throat complaints after tracheal intubation [26, 27]. In their study, Hermite et al. compared two different supraglottic airway devices (LMA-S, and Laryngeal Mask Airway Unique (LMA-U)) with an intracuff pressure of $60 \mathrm{cmH}_{2} \mathrm{O}$; they reported no significant differences between the LMA-S and other airway devices in terms of postoperative sore throat [28]. For this reason, in our study, we used an intracuff pressure of $60 \mathrm{cmH}_{2} \mathrm{O}$ as a reference. Barreriera et al. compared LMA-S and ETT use in their study and found that the incidence of sore throat was significantly higher in the ETT group using a ETT cuff pressure of $25-30 \mathrm{~mm}$ $\mathrm{cmH}_{2} \mathrm{O}$ [29]. Similarly, Radu et al. compared ETT and LMA use in breast surgery patients and found incidences of sore throat at the 6th postoperative hour to be significantly higher with the ETT [30]. Similarly, in our study, sore throat complaints were significantly lower in the LMA-S group at the 2nd, 6th, and 12th postoperative hours $(p=0.003, p=0.017$ and $p<0.001$, respectively). Therefore, we believe that the LMA-S causes fewer sore throats at appropriate intracuff pressures in septoplasty cases than the ETT.

\section{Limitations}

Our study had some limitations. First, in the ETT group, the presence of blood at the vocal cord level was evaluated visually by the presence of blood on the cuff after extubation, since it was not possible to assess it with a flexible bronchoscope. Secondly, the amount of bleeding 
Table 5 Postoperative adverse events

\begin{tabular}{|c|c|c|c|c|c|c|c|c|c|c|c|c|}
\hline \multirow{3}{*}{$\begin{array}{l}\text { Variable } \\
\text { Postoperative } \\
\text { period }\end{array}$} & \multicolumn{4}{|c|}{ LMA-S $(n=40)$} & \multicolumn{4}{|c|}{$\mathrm{ETT}(n=40)$} & \multirow{2}{*}{\multicolumn{4}{|c|}{$p$ values }} \\
\hline & \multicolumn{4}{|l|}{$\begin{array}{l}\mathrm{n} \\
(\%)\end{array}$} & \multicolumn{4}{|l|}{$\begin{array}{l}\mathrm{n} \\
(\%)\end{array}$} & & & & \\
\hline & 2nd hour & 6th hour & $\begin{array}{l}\text { 12th } \\
\text { hour }\end{array}$ & $\begin{array}{l}\text { 24th } \\
\text { hour }\end{array}$ & 2nd hour & 6th hour & $\begin{array}{l}\text { 12th } \\
\text { hour }\end{array}$ & $\begin{array}{l}\text { 24th } \\
\text { hour }\end{array}$ & $\overline{P_{2 n d}{ }^{a}}$ & $P_{6 t h}^{a}$ & $\mathrm{P}_{12 \mathrm{th}}{ }^{\mathrm{a}}$ & $P_{24 h}{ }^{a}$ \\
\hline $\begin{array}{l}\text { Sore throat } \\
\text { (None/mild/ } \\
\text { moderate/severity) }\end{array}$ & $\begin{array}{l}28 / 8 / 4 / 0 \\
(70 / 20 / 10 / \\
0)\end{array}$ & $\begin{array}{l}28 / 11 / 1 / 0 \\
(70 / 28 / 2 / 0)\end{array}$ & $\begin{array}{l}37 / 3 / 0 / 0 \\
(92.5 / 7.5 / \\
0 / 0)\end{array}$ & $\begin{array}{l}39 / 1 / 0 / 0 \\
(97.5 / 2.5 / \\
0 / 0)\end{array}$ & $\begin{array}{l}15 / 8 / 14 / 3 \\
(37.5 / 20 / \\
35 / 7.59\end{array}$ & $\begin{array}{l}16 / 17 / 6 / 1 \\
(40 / 42.5 / \\
15 / 2.5)\end{array}$ & $\begin{array}{l}22 / 14 / 4 / \\
0 \\
(55 / 35 / \\
10 / 0)\end{array}$ & $\begin{array}{l}39 / 1 / 0 / 0 \\
(97.5 / 2.5 / \\
0 / 0)\end{array}$ & 0.003 & 0.017 & $\begin{array}{l}< \\
0.001\end{array}$ & 0.057 \\
\hline $\begin{array}{l}\text { Nausea-vomiting } \\
(0 / 1 / 2 / 3)^{\mathrm{a}}\end{array}$ & $\begin{array}{l}28 / 7 / 5 / 0 \\
(70 / 17.5 / \\
12.5 / 0)\end{array}$ & $\begin{array}{l}35 / 3 / 1 / 1 \\
887.5 / 7.5 / \\
2.5 / 2.5)\end{array}$ & $\begin{array}{l}38 / 1 / 1 / 0 \\
(95 / 2.5 / \\
2.5 / 0)\end{array}$ & $\begin{array}{l}39 / 1 / 0 / 0 \\
(97.5 / 2.5 / \\
0 / 0)\end{array}$ & $\begin{array}{l}29 / 4 / 6 / 1 \\
(72.5 / 10 / \\
15 / 2.5)\end{array}$ & $\begin{array}{l}36 / 0 / 4 / 0 \\
(90 / 0 / 10 / \\
0)\end{array}$ & $\begin{array}{l}39 / 1 / 0 / 0 \\
(97.5 / 2.5 / \\
0 / 0)\end{array}$ & $\begin{array}{l}40 / 0 / 0 / 0 \\
(100 / 0 / 0 / \\
0)\end{array}$ & 0.76 & 0.12 & 0.61 & 1 \\
\hline $\begin{array}{l}\text { Dysphagia } \\
\text { (Absent/present) }\end{array}$ & $\begin{array}{l}35 / 5 \\
(87.5 / \\
12.59)\end{array}$ & $\begin{array}{l}39 / 1 \\
(97.5 / 2.59)\end{array}$ & $\begin{array}{l}40 / 0 \\
(100 / 0)\end{array}$ & $\begin{array}{l}40 / 0 \\
(100 / 0)\end{array}$ & $\begin{array}{l}33 / 7 \\
(82.5 / 17.5)\end{array}$ & $\begin{array}{l}34 / 6 \\
(85 / 15)\end{array}$ & $\begin{array}{l}37 / 3 \\
(92.5 / 7.5)\end{array}$ & $\begin{array}{l}37 / 3 \\
(92.5 / 7.5)\end{array}$ & 0.75 & 0.10 & 0.24 & 0.24 \\
\hline $\begin{array}{l}\text { Dysphonia } \\
\text { (Absent/present) }\end{array}$ & $\begin{array}{l}38 / 2 \\
(95 / 5)\end{array}$ & $\begin{array}{l}37 / 3 \\
(92.5 / 7.5)\end{array}$ & $\begin{array}{l}38 / 2 \\
(95 / 5)\end{array}$ & $\begin{array}{l}39 / 1 \\
(97.5 / 2.5)\end{array}$ & $\begin{array}{l}37 / 3 \\
(92.5 / 7.5)\end{array}$ & $\begin{array}{l}37 / 3 \\
(92.5 / 7.5)\end{array}$ & $\begin{array}{l}38 / 2 \\
(95 / 5)\end{array}$ & $\begin{array}{l}39 / 1 \\
(97.5 / \\
2.59)\end{array}$ & 1 & 1 & 1 & 1 \\
\hline
\end{tabular}

${ }^{a}$ Nausea and vomiting score: $0=$ none, $1=$ mild-moderate nausea, $2=$ vomiting less than 2 times per hour, $3=$ vomiting more than 2 times per hour; a: Pearson chi-square test

in the airway could not be measured due to technical difficulties of aspiration and the risk of undesirable airway reflexes (laryngospasm, bronchospasm).

\section{Conclusion}

As evident in our findings, we have determined that the LMA-S is superior to the ETT in protecting the airway against blood contamination and reducing postoperative sore throat associated with general anesthesia in septoplasty surgeries. We also believe that the LMA-S may be a more reliable and better alternative to the ETT for airway management in septoplasty surgeries.

\section{Abbreviations}

LMA-S: Laryngeal Mask Airway-Supreme; ETT: Endotracheal tube;

OLP: Oropharyngeal leakage pressure; HR: Heart rate; MAP: Mean arterial pressure; ASA: American Society of Anesthesiologists; BMI: Body mass index; VAS: Visual analogue scale; NRS: Numeric rating scale

\section{Acknowledgements}

Not Applicable.

\section{Authors' contributions}

EK, SA, ASO, ZB and CC collected and analyzed the data. EK and SA wrote the manuscript draft. ZB and ASO helped with the study design and interpretation of the data. EK and CÇ helped to collect and analyze the data. EK conceived the idea, designed the study, interpreted the data, and rewrote the manuscript. All authors read and approved the final manuscript.

\section{Funding}

The author(s) received no financial support for the research, authorship, and/ or publication of this article.

\section{Availability of data and materials}

The datasets analyzed during the current study are available from the corresponding author on reasonable request.

\section{Ethics approval and consent to participate}

The study was approved by the Local Ethic Committee of Inonu University (Protocol no: 2018/165) and this trial is registered at the US National Institutes of Health (ClinicalTrials.gov) \# NCT03903679 on April 5, 2019. The patients agreed to participate in the study voluntarily. After they were informed about the potential risks and predicted results of the study, they completed the written informed consent forms.

Consent for publication

Not applicable.

\section{Competing interests}

The authors declare that they have no competing interests.

\section{Author details}

'Department of Anesthesiology and Reanimation, Inonu University Medical Faculty, Malatya, Turkey. ${ }^{2}$ Department of Biostatistics and Medical Informatics, Inonu University Medical Faculty, Malatya, Turkey.

Published online: 07 January 2021

\section{References}

1. Kohli M, Wadhawan S, Bhadoria P, Ratan SK. Comparative evaluation of I-gel vs. endotracheal intubation for adequacy of ventilation in pediatric patients undergoing laparoscopic surgeries. J Anaesthesiol Clin Pharmacol. 2019; 35(1):30-5.

2. Ozden ES, Meco BC, Alanoglu Z, Alkıs N. Comparison of ProSeal TM laryngeal mask airway (PLMA) with cuffed and uncuffed endotracheal tubes in infants. Bosn J Basic Med Sci. 2016;16(4):286-91.

3. Beleña JM, Núñez M, Anta D, Carnero M, Gracia JL, Ayala JL. Comparison of Laryngeal Mask Airway Supreme and Laryngeal Mask Airway Proseal with respectto oropharyngeal leak pressure during laparoscopic cholecystectomy: a randomised controlled trial. Eur J Anaesthesiol. 2013; 30(3):119-23.

4. Teoh WHL, Lee KM, SuhitharanTZ YMM, Teo AT, Sia H. Comparison of the LMA Supreme vs the $\mathrm{i}-\mathrm{gel}^{\mathrm{TM}}$ in paralysed patients undergoing gynaecological laparoscopic surgery with controlled ventilation. Anaesthesia. 2010;65:1173-9.

5. López AM, Valero R, Hurtado P, Gambús P, Pons M, Anglada T. Comparison of the LMA Supreme with the LMA Proseal for airway management in patients anaesthetized in prone position. Br J Anaesth. 2011;107:265-71.

6. Woodall NM, Cook TM. National census of airway management techniques used for anaesthesia in the UK: first phase of the fourth National Audit Project at the Royal College of Anaesthetists. Br J Anaesth. 2011;106(2):26671. https://doi.org/10.1093/bja/aeq339 Epub 2010 Dec 4.

7. Mao S, Du X, Ma J, Zhang G, Cui JA. Comparison between laryngeal mask airway and endotracheal intubation for anaesthesia in adult patients undergoing NUSS procedure. J Thorac Dis. 2018;10(6):3216-24. 
8. Verghese C, Ramaswamy B. LMA-supreme a new single-use LMA with gastric access: a report on its clinical efficacy. Br J Anaesth. 2008;101(3):405-10.

9. Kaplan A, Crosby GJ, Bhattacharyya N. Airway protection and the laryngeal mask airway in sinus and nasal surgery. Laryngoscope. 2004;114(4):652-5.

10. Schulz KF, Altman DM, CONSORT Group. CONSORT 2010 statement: updated guidelines for reporting parallel group randomised trials. Int J Surg. 2011;9:672-7.

11. Tiefenthaler W, Eschertzhuber S, Brimacombe J, Fricke E, Keller C, Kaufmann M. A randomised, non-crossover study of the Guardian CPV laryngeal mask versus the LMA supreme in paralysed, anaesthetised female patients. Anaesthesia. 2013;68:600-4.

12. Verghese C, Berlet J, Kapila A, Pollard R. Clinical assessment of the single use laryngeal mask airway-the LMA-unique. Br J Anaesth. 1998 May:80(5):677-9.

13. Moser B, Keller C, Audigé L, Bruppacher HR. Oropharyngeal leak pressure of the LMA protector ${ }^{\mathrm{TM}}$ vs the LMA supreme ${ }^{\mathrm{TM}}$; a prospective, randomized, controlled clinical trial. Acta Anaesthesiol Scand. 2019;63(3):322-8.

14. Sinha A, Sharma B, Sood J. ProSeal as an alternative to endotracheal intubation in pediatric laparoscopy. Paediatr Anaesth. 2007;17(4):327-9.

15. Keller $C$, Brimacombe JR, Keller K, Morris R. Comparison of four methods for assessing airway sealing pressure with the laryngeal mask airway in adult patients. Br J Anaesth. 1999;82:286-7.

16. Ready LB, Oden R, Chadwick HS, Benedetti C, Rooke GA, Caplan R, Wild LM. Development of anesthesiology-based postoperative pain management service. Anesthesiology. 1988;68:100-6.

17. Brimacombe J, Holyoake L, Keller C, Brimacombe N, Scully M, Barry J, Talbutt P, Sartain J, McMahon P. Pharyngolaryngeal, neck, and jaw discomfort after anesthesia with the face mask and laryngeal mask airway at high and low cuff volumes in males and females. Anesthesiology. 2000;93(1):26-31.

18. Aldrete JA, Kroulik DA. A postanesthetic recovery score. Anesth Analg. 1970; 49:924-34.

19. Al-Mazrou KA, Abdullah KM, El Gammal MS, Ansari RA, Turkistani A, Abdelmeguid ME. Laryngeal mask airway vs. uncuffed endotracheal tube for nasal and paranasal sinus surgery: paediatric airway protection. Eur J Anaesthesiol. 2010;27(1):16-9.

20. AhmedMZ VA. The reinforced laryngeal mask airway (RLMA) protects the airway in patients undergoing nasal surgery an observational study of 200 patients. Can J Anaesth. 2002:49(8):863-6.

21. Williams PJ, Bailey PM. Comparison of the reinforced laryngeal mask airway and tracheal intubation for adenotonsillectomy. Br J Anaesth. 1993;70:30-3.

22. Aldrete JA. The postanesthetic recovery score revisited. J Clin Anesth. 1995; 7:89-91.

23. Maitra S, Baidya DK, Arora MK, Bhattacharjee S, Khanna P. Laryngeal mask airway ProSeal provides higher oropharyngeal leak pressure than i-gel in adultpatients under general anesthesia: a meta-analysis. J Clin Anesth. 2016; 33:298-30.

24. Seet E, Rajeev S, Firoz T, Yousaf F, Wong J, David T. Safety and efficacy of laryngeal mask airway supreme versus laryngeal mask airway ProSeal ${ }^{\mathrm{T}}$ : a randomized controlled trial. Eur J Anaesthesiol. 2010;27:602-7.

25. Zhang L, Seet E, Mehta V, Subramanyam R, Ankichetty SP, Wong DT. Oropharyngeal leak pressure with the laryngeal mask airway Supreme ${ }^{\mathrm{TM}}$ at different intracuff pressures: a randomized controlled trial. Can J Anaesth. 201:58(7):624-9.

26. Chen KT, Tzeng Jl, Lu CL, Liu KS, Chen YW, Hsu CS. Risk factors associated with postoperative sore throat after tracheal intubation: an evaluation in the postanesthetic recovery room. Acta Anaesthesiol Taiwanica. 2004;42(1):3-8.

27. Higgins PP, Chung F, Mezei G. Postoperative sore throat after ambulatory surgery. Br J Anaesth. 2002;88:582-4.

28. L'Hermite J, Dubout E, Bouvet S, Bracoud LH, Cuvillon P, Coussaye JE. Sore throat following three adult supraglottic airway devices: a randomised controlled trial. Eur J Anaesthesiol. 2017;34(7):417-24.

29. Barreira SR, Sousa CM, Fabrizia F, Azevedom AB, Lelis TG, Lutke C Prospective randomized clinical trial of laryngeal mask airway supreme ${ }^{\oplus}$ used in patients undergoing general anesthesia. Rev Bras Anestesiol. 2013; 63:456-60.

30. Radu AD, Miled F, Marret E, Vigneau A, Bonnet F. Pharyngo-laryngeal discomfort after breast surgery: comparison between orotracheal intubation and laryngeal mask. Breast. 2008;17(4):407-11.

\section{Publisher's Note}

Springer Nature remains neutral with regard to jurisdictional claims in published maps and institutional affiliations.

Ready to submit your research? Choose BMC and benefit from:

- fast, convenient online submission

- thorough peer review by experienced researchers in your field

- rapid publication on acceptance

- support for research data, including large and complex data types

- gold Open Access which fosters wider collaboration and increased citations

- maximum visibility for your research: over $100 \mathrm{M}$ website views per year

At $\mathrm{BMC}$, research is always in progress.

Learn more biomedcentral.com/submissions 